\title{
MicroRNA-363 targets myosin 1B to reduce cellular migration in head and neck cancer

Bhavana V. Chapman ${ }^{1,3,6+}$, Abigail I. Wald ${ }^{1 \dagger}$, Parvez Akhtar ${ }^{1}$, Ana C. Munko ${ }^{1}$, Jingjing Xu' ${ }^{1}$, Sandra P. Gibson ${ }^{2,3}$, Jennifer R. Grandis ${ }^{3,4,5}$, Robert L. Ferris ${ }^{2,3}$ and Saleem A. Khan ${ }^{1 *}$

\begin{abstract}
Background: Squamous cell carcinoma of the head and neck (SCCHN) remains a prevalent and devastating disease. Recently, there has been an increase in SCCHN cases that are associated with high-risk human papillomavirus (HPV) infection. The clinical characteristics of HPV-positive and HPV-negative SCCHN are known to be different but their molecular features are only recently beginning to emerge. MicroRNAs (miRNAs, miRs) are small, non-coding RNAs that are likely to play significant roles in cancer initiation and progression where they may act as oncogenes or tumor suppressors. Previous studies in our laboratory showed that miR-363 is overexpressed in HPV-positive compared to HPV-negative SCCHN cell lines, and the HPV type 16-E6 oncoprotein upregulates miR-363 in SCCHN cell lines. However, the functional role of miR-363 in SCCHN in the context of HPV infection remains to be elucidated.
\end{abstract}

Methods: We analyzed miR-363 levels in SCCHN tumors with known HPV-status from The Cancer Genome Atlas (TCGA) and an independent cohort from our institution. Cell migration studies were conducted following the overexpression of miR-363 in HPV-negative cell lines. Bioinformatic tools and a luciferase reporter assay were utilized to confirm that miR-363 targets the 3'-UTR of myosin 1B (MYO1B). MYO1B mRNA and protein expression levels were evaluated following miR-363 overexpression in HPV-negative SCCHN cell lines. Small interfering RNA (siRNA) knockdown of MYO1B was performed to assess the phenotypic implication of reduced MYO1B expression in SCCHN cell lines.

Results: MiR-363 was found to be overexpressed in HPV-16-positive compared to the HPV-negative SCCHN tumors. Luciferase reporter assays performed in HPV-negative JHU028 cells confirmed that miR-363 targets one of its two potential binding sites in the $3^{\prime} U T R$ of MYO1B. MYO1B mRNA and protein levels were reduced upon miR-363 overexpression in four HPV-negative SCCHN cell lines. Increased miR-363 expression or siRNA knockdown of MYO1B expression reduced Transwell migration of SCCHN cell lines, indicating that the miR-363-induced migration attenuation of SCCHN cells may act through MYO1B downregulation.

Conclusions: These findings demonstrate that the overexpression of miR-363 reduces cellular migration in head and neck cancer and reveal the biological relationship between miR-363, myosin 1b, and HPV-positive SCCHN.

Keywords: Squamous cell carcinoma of the head and neck, Human papillomavirus, miR-363, Myosin 1B

\section{Background}

Head and neck cancer ranks sixth amongst cancers worldwide and represents a heterogeneous collection of neoplasms, derived from the upper aerodigestive tract $[1,2]$. The most common type, squamous cell carcinoma of the head and neck (SCCHN), occurs in the oral cavity, pharynx, and larynx. Tobacco use and alcohol

\footnotetext{
* Correspondence: khan@pitt.edu

${ }^{\dagger}$ Equal contributors

'Department of Microbiology and Molecular Genetics, University of

Pittsburgh School of Medicine, Pittsburgh, PA 15219, USA

Full list of author information is available at the end of the article
}

consumption are the predominant risk factors for SCCHN. Recently, human papillomavirus (HPV) infection has been noted as an etiologic agent for a subset of SCCHN, specifically oropharyngeal malignancies, including tumors of the base of tongue and tonsil [3]. Despite advances in diagnosis and treatment, the five-year survival rate of $40-50 \%$ has only incrementally improved in the last 20 years [4]. Prophylactic vaccination against high-risk HPV types may prevent a substantial number of oropharyngeal carcinomas in the future. However, the prolonged course of HPV carcinogenesis and the current 
prevalence of HPV-positive SCCHN warrant further investigation of its pathogenesis.

HPVs are small, circular, double-stranded, nonenveloped DNA viruses that infect the basal layer of squamous epithelial cells through abrasions or lesions in skin or mucosa. The relationship between high-risk HPV types (for example, HPV-16 and HPV-18) and cervical, anogenital, and oral cancers is well-established [5]. E6 and E7 oncoproteins from high-risk HPV types are essential for cellular transformation and functional inactivation of the tumor suppressor proteins p53 and retinoblastoma, respectively [1].

While the overall incidence of SCCHN has steadily declined, the prevalence of HPV-positive SCCHN cancers, specifically in developed nations, has markedly increased in the past decade due to a shift in sexual practices. SCCHN patient tumors from the United States demonstrate a $30 \%$ HPV positivity rate [5], with more than $90 \%$ of HPV-associated SCCHN due to HPV-16 [5]. HPV-positive and HPV-negative SCCHN demonstrate different clinical and demographic characteristics, leading some to classify them as distinct cancers [6]. HPVpositive SCCHN patients are generally younger men (40-55 years) from a higher socioeconomic status with minimal tobacco and alcohol exposure [5]. Tumors with a high viral load generally have a better prognosis compared to HPV-negative or low viral load tumors [7]. Despite late stage presentations due to early metastasis to secondary lymphoid tissues [8], HPV-positive tumors have a greater response to chemotherapy, radiation, and surgery [8]. HPV-positive tumors demonstrate improved immune system activation to viral antigens [9], lower recurrence rates [10], and more favorable disease outcomes [1] compared to HPV-negative head and neck tumors. While p53 contains inactivating mutations in more than half of HPV-negative oral cancers, it is rarely mutated in HPV-positive SCCHN [8]. The complex molecular mechanisms underlying the divergence in outcome depending on HPV-status is not well-understood. Elucidating the role of microRNAs (miRNAs, miRs) is one approach to evaluating the molecular differences between HPV-positive versus HPV-negative SCCHN.

MiRNAs are $\sim 22$ nucleotide-long, endogenously encoded, single-stranded RNAs that modulate the expression of over $50 \%$ of human genes at the posttranscriptional level $[11,12]$. MiRNAs are transcribed either from their own promoters or are processed from introns of protein-coding genes [13]. Precursor miRNAs ( 70 nucleotides long) are exported into the cytoplasm where they are further processed into mature miRNAs and incorporated into the RNA-induced silencing complex (RISC) as a single strand [14]. RISC-associated miRNAs then pair with complementary sequences in the 3'-untranslated regions (UTRs) of one or more target
mRNAs [14]. MiRNAs function as negative posttranscriptional regulators of gene expression by several mechanisms, including (1) site-specific cleavage of mRNAs; (2) enhanced mRNA degradation; and (3) inhibition of mRNA translation [14]. An mRNA may be targeted by several miRNAs while a single miRNA may target multiple mRNAs, thereby regulating dozens of genes.

MiRNAs regulate several cellular processes such as proliferation, differentiation, and apoptosis. Studies in chronic lymphocytic leukemia were the first to reveal the relationship between miRNAs and cancer pathogenesis in 2002 [15]. Since then, aberrant miRNA expression has been implicated in the initiation and progression of numerous hematological cancers and solid tumors, including SCCHN [16-18]. Notably, differential miRNAs expression profiles have been described in noncancerous versus tumor tissues [16, 19, 20]. MiRNAs may function as tumor suppressors or oncogenes depending on whether they target the mRNA of oncogenes or tumor suppressors, respectively. Consequently, confirming protein targets of a miRNA is critical in delineating their role in cancer. However, while several SCCHN miRNA profiling studies have been recently performed, the functional significance of dysregulated miRNAs in SCCHN is still poorly understood, especially in the context of HPV infection [20-31].

Although miR-363 is a member of the oncogenic miR$17 \sim 92$ family of clusters [32], recent studies indicate that it may also possess tumor suppressor functions [33-36]. Thus, its role in oncogenesis is rather controversial at the present time. We previously reported miR363 overexpression in HPV-positive SCCHN cell lines and showed that the HPV-16 E6 oncogene directly upregulates miR-363 [30]. In the current study, we have interrogated miR-363 expression in human SCCHN tumors and the phenotypic significance of miR-363 overexpression in SCCHN cell lines. MiRNA target prediction analysis suggested that miR-363 may target the 3'UTR of myosin 1B (MYO1B), a motor protein involved in cellular motility $[37,38]$. Using luciferase reporter assays, we confirmed that miR-363 downregulates MYO1B expression in SCCHN cells by directly targeting the 3'UTR of MYO1B mRNA. By investigating the consequences of HPV-16 E6-mediated miR-363 expression in vitro, we aim to better resolve the clinicopathological features of HPV-positive SCCHN and identify prognostic markers of disease outcome, as well as new targets and therapeutic agents.

\section{Methods \\ Patients}

This study was approved by the Institutional Review Board of the University of Pittsburgh (protocol \#99-069). 
Written informed consent was obtained from all patients. No children were enrolled in this study.

\section{Bioinformatics}

MicroRNA data were extracted from The Cancer Genome Atlas (TCGA) Research Network (http://cancergenome.nih.gov/) portal isoform files for SCCHN tumors (accessed May 15, 2013). The reads per million miRNAs mapped data unit was evaluated, which represents each miRNA read count as a fraction of the total miRNA population for a particular tumor. Multiple reads from individual isoforms were combined into a single read count. The HPV-status of TCGA SCCHN tumors was noted according to the cBio Cancer Genomics Platform SCCHN database [39].

\section{SCCHN tumors}

Forty-one SCCHN tissues were obtained from patients according to Institutional Review Board protocol \#99069. Upon surgical removal, a portion of all tissues was sent to pathology for tumor staging and the remainder was flash frozen until further processing.

\section{Cell lines and maintenance}

The HPV-negative human SCCHN cell lines PCI13 and PCI30 were kindly provided by Dr. Theresa Whiteside (University of Pittsburgh Cancer Institute, Pittsburgh, PA) while the JHU028 and JHU029 cell lines were obtained from Dr. Joseph A. Califano (Johns Hopkins University School of Medicine, Baltimore, MD). PCI13 and PCI30 were cultured in Dulbecco's Modified Eagle's Medium (Lonza, Walkersville, MD) while JHU028 and JHU029 were cultured in RPMI-1640 (Lonza). All cells were supplemented with $10 \%$ heat-inactivated FBS, $1 \mathrm{X}$ penicillin/streptomycin solution (Lonza), and $2 \mathrm{mM} \mathrm{L-}$ glutamine (Gibco). Cell lines were maintained in a humidified cell incubator at $37^{\circ} \mathrm{C}, 5 \% \mathrm{CO}_{2}$ atmosphere.

\section{Transfections}

Cells were seeded to $50 \%$ confluency in 6-well plates in antibiotic-free media $24 \mathrm{~h}$ prior to transfection. Cells were transfected with $50 \mathrm{nM}$ premiR-363, negative premiR control (Applied Biosystems, Foster City, CA), or $50 \mathrm{nM}$ small interfering RNA (siRNA) against MYO1B (ThermoFisher Scientific, San Jose, CA) using Lipofectamine 2000 (Invitrogen, Carlsbad, CA) and Opti-MEM ${ }^{\circ}$ (Gibco, Grand Island, NY). A FAM-labeled control premiR (Applied Biosystems) or a Block-it fluorescent oligonucleotide with no human homologous sequences (Invitrogen) was used as a control and to measure transfection efficiency in premiR and siRNA experiments, respectively. Cells were harvested $48 \mathrm{~h}$ after transfection and RNA and proteins were isolated for various assays as described below.

\section{DNA and RNA isolation}

The Dneasy Blood \& Tissue kit (Qiagen, Valencia, CA) was used to isolate DNA from SCCHN tissues according to the manufacturer's protocol. Total RNA was isolated from SCCHN tissues and cell lines grown to 80-90 \% confluency using the Ultraspec ${ }^{\mathrm{TM}}$ RNA Isolation System (Biotecx, Houston, TX) according to the manufacturer's protocol.

\section{HPV genotyping and quantitative real time RT-PCR}

HPV status of the tumor tissues was assessed using the MY09/MY11 primer set, which amplifies a conserved region of the HPV L1 gene [40]. The glyceraldehyde-3phosphate dehydrogenase $(\mathrm{GAPDH})$ gene was used as a loading control using 5 '-CGACCACTTTGTCAAGCTCA$3^{\prime}$ as the forward primer and 5'-AGGGGTCTACATG GCAACTG-3' as the reverse primer. All PCR reactions were performed using $20 \mathrm{ng}$ template DNA, $200 \mu \mathrm{M}$ of each deoxynucleoside triphosphate (dNTP), $0.5 \mu \mathrm{M}$ of each primer, and 0.5 units of Taq polymerase and the associated buffer (Promega, Madison, WI). Thermocycler conditions for all PCR reactions were $94{ }^{\circ} \mathrm{C}$ for $5 \mathrm{~min}$; 35 cycles of $94^{\circ}$ $\mathrm{C}$ for $30 \mathrm{~s}, 57{ }^{\circ} \mathrm{C}$ for $30 \mathrm{~s}$, and $72{ }^{\circ} \mathrm{C}$ for $30 \mathrm{~s}$; and $72{ }^{\circ} \mathrm{C}$ for $10 \mathrm{~min}$. The PCR-amplified DNA was visualized by agarose gel electrophoresis.

HPV-16 E6, HPV-16 E7, and MYO1B expression levels were measured by quantitative real-time RT-PCR (qRTPCR) using the iTaq ${ }^{\text {TM }}$ Universal SYBR Green One-Step Kit (Bio-Rad) and the Real-Time thermocycler iQ5 (Bio-Rad, Hercules, CA, USA). The E6 forward primer 5'-AATGTTTCAGGACCCACAGG-3', E6 reverse primer 5'-CAGCTGGGTTTCTCTACGTG-3', E7 forward primer 5'-CATGGAGATACACCTACATTGCAT-3', and E7 reverse primer 5'-GAACAGATGGGGCAC ACAAT-3' were used to genotype HPV-positive SCCHN tissue samples. A 127 bp region of the MYO1B gene was amplified using the forward primer $5^{\prime}$-GGTCTGGT GTGGAGGTCCTA-3' and the reverse primer $5^{\prime}$ CGTTGCTTCCTCAGGTCTTC-3'. HPV-16 E6, HPV$16 \mathrm{E7}$, and MYO1B mRNA levels were normalized to the GAPDH mRNA levels, using the forward primer 5 ' CAGCCTCAAGATCATCAGCA-3' and the reverse primer 5'-TGTGGTCATGAGTCCTTCCA-3', amplifying a 106 bp region. DNase I-treated total RNA (60 ng) was used for each reaction, and all the reactions were performed in triplicate. Relative mRNA expression levels were calculated using the $2^{-\Delta \Delta C T}$ values [41].

Mature miR-363 expression was confirmed by qRTPCR using the TaqMan MicroRNA Reverse Transcription Kit and the TaqMan MicroRNA Assays (Applied Biosystems, Foster City, CA, USA) and the Real-Time thermocycler iQ5 (Bio-Rad, Hercules, CA, USA). The qRT-PCR experiments utilized stem-loop primers designed to amplify processed, mature miRNA. Total RNA (50 ng) was used for each reaction. All reactions were 
performed in triplicate according to the manufacturer's instructions. MiRNA levels for each sample were normalized to small nucleolar (sno) RNU43 levels. Relative miRNA expression levels were calculated using the 2 $\Delta \Delta C T$ values [41].

\section{Transwell migration assay}

The HPV-negative SCCHN cell line, JHU028, was transfected with premiR-363 or an siRNA against MYO1B along with appropriate controls as described earlier. Forty-eight hours after transfection, cells were harvested and reseeded into 24-well $8 \mu \mathrm{M}$ pore Transwell inserts (Corning) in serum-free media. The lower chambers of the Transwell plate were filled with $20 \% \mathrm{FBS} / \mathrm{RPMI}$ media to serve as a chemoattractant. Transwells were stained with $0.1 \%$ crystal violet at 1,3 , and $5 \mathrm{~h}$ following reseeding. Cells were photographed under the microscope and counted. The mean of eight fields from four separate trials was used to calculate the average number of migratory cells.

\section{Mutagenesis of the miR-363 binding sites in the MYO1B 3' UTR}

The MYO1B 3'UTR (1.4 kb; chr2:192,288,687192,290,115) was PCR amplified using the forward primer 5'-GGACTAGTAACCGTCTCCTTGAAGTTGC-3' and the reverse primer 5'-GGAAGCTTGGCACAAG GCAAGAAGAATC-3'. The primers were designed with a SpeI restriction site on the forward primer and a HindIII site on the reverse primer to aid in directional cloning of the amplified DNA into the pMIR-REPORT ${ }^{\mathrm{TM}}$ vector (Applied Biosystems). The orientation of the inserted fragment was confirmed by restriction enzyme digestion and sequencing.

Deletion primers and the QuikChange XL Site-Directed Mutagenesis Kit (Agilent Technologies; Santa Clara, CA) was used to delete miR-363 binding site 1 (BS1) (chr2:192,288,731-192,288,738) or binding site 2 (BS2) (chr2: 192,289,618-192,289,625) from the 3'UTR of the MYO1B gene cloned into the pMIR-REPORT ${ }^{\mathrm{TM}}$ vector (Applied Biosystems). BS1 was deleted using the forward primer 5'CTACTTTCATGGACTTGTTCCTTTGTAAT A-TGGTTTTGTTTTATTTGGGGTTCATTGTATG-3' and the reverse primer 5'-CATACAATGAACCCCAAA TAAAACAAAACCA-TATTACAAAGGAACAAGTCCA TGAAAGTAG-3'. BS2 was deleted using the forward primer 5'-CCATTCAGATAGCAGTAAAACATTCTG TATGAT-AAACATCCAAGATCTTTTTTGAAAG-3' and the reverse primer 5'CTTTCAAAAAAGATCTTGGAT GTTT-ATCATACAGAATGTTTTACTGCTATCTGAA TGG-3'. Deletion mutants were confirmed by restriction enzyme digestion and DNA sequencing.

\section{Luciferase reporter assay}

HPV-negative JHU028 cells were plated at 30,000 cells per well in 24-well plates (Corning). After $24 \mathrm{~h}$, cells were transfected using Lipofectamine 2000 (Invitrogen) and Opti-MEM ${ }^{\circ}$ (Life Technologies). The pMIRREPORT $^{\text {TM }}$ MYO1B wild-type, 3'UTR BS1 or BS2 deletion constructs (500 ng) were co-transfected with $20 \mathrm{ng}$ phRL-TK and $50 \mathrm{nM}$ pre-miRs. All transfection experiments were repeated at least four times. Luciferase activity was measured $48 \mathrm{~h}$ post-transfection using the Dual Luciferase Reporter Assay System (Promega) according to manufacturer's instructions and the Synergy 2 Luminometer (Biotek). RLU (Firefly/Renilla) activity was normalized to the MYO1B wild-type 3' UTR co-transfected with phRL-TK only.

\section{Western blotting}

Cells were lysed with radioimmunoprecipitation assay (RIPA) buffer at $4{ }^{\circ} \mathrm{C}$ directly on the 6 well-plate $48 \mathrm{~h}$ post-transfection with premiR-363 and the premiR negative control. Proteins $(50 \mu \mathrm{g})$ from total cell lysates were separated on a 4-15\% SDS-polyacrylamide gradient gel (Bio-Rad) and transferred to Immobilon-P PVDF membrane (Millipore, Billerica, MA). After blocking, blots were incubated with a primary rabbit polyclonal antibody against MYO1B and a secondary anti-rabbit horseradish peroxidase antibody (both Santa Cruz Biotechnology, Santa Cruz, CA). A mouse monoclonal antibody against GAPDH (Chemicon, Billerica, MA) was used to normalize protein loading. Blots were visualized using the Western Lightning Plus ECL Substrate (Perkin Elmer; Waltham, MA), developed, and quantified by densitometry using AlphaView software by ProteinSimple (Santa Clara, CA).

\section{Statistical analysis}

Statistical analysis was carried out using two-tailed t-tests. Data was considered significant at a value of $p<0.05$.

\section{Results}

MiR-363 expression is significantly upregulated in head and neck tumors

Our analysis of 280 TCGA SCCHN tumors (245 HPVnegative and $35 \mathrm{HPV}$-positive) revealed that miR-363 expression is significantly increased $(p<0.001)$ in HPVpositive tumors compared to HPV-negative tumors (Figure 1a) [42]. We also examined an additional cohort of $41 \mathrm{SCCHN}$ patients (24 HPV-positive and $17 \mathrm{HPV}$ negative tumors) treated at the University of Pittsburgh Cancer Institute (UPCI) between 2006 and 2009 (Fig. 1b, Table 1). Patient characteristics are further described in detail in Additional file 1. DNA PCR was performed to confirm the HPV status of tumor tissues (data not shown). HPV-positive SCCHN tissues expressed higher 


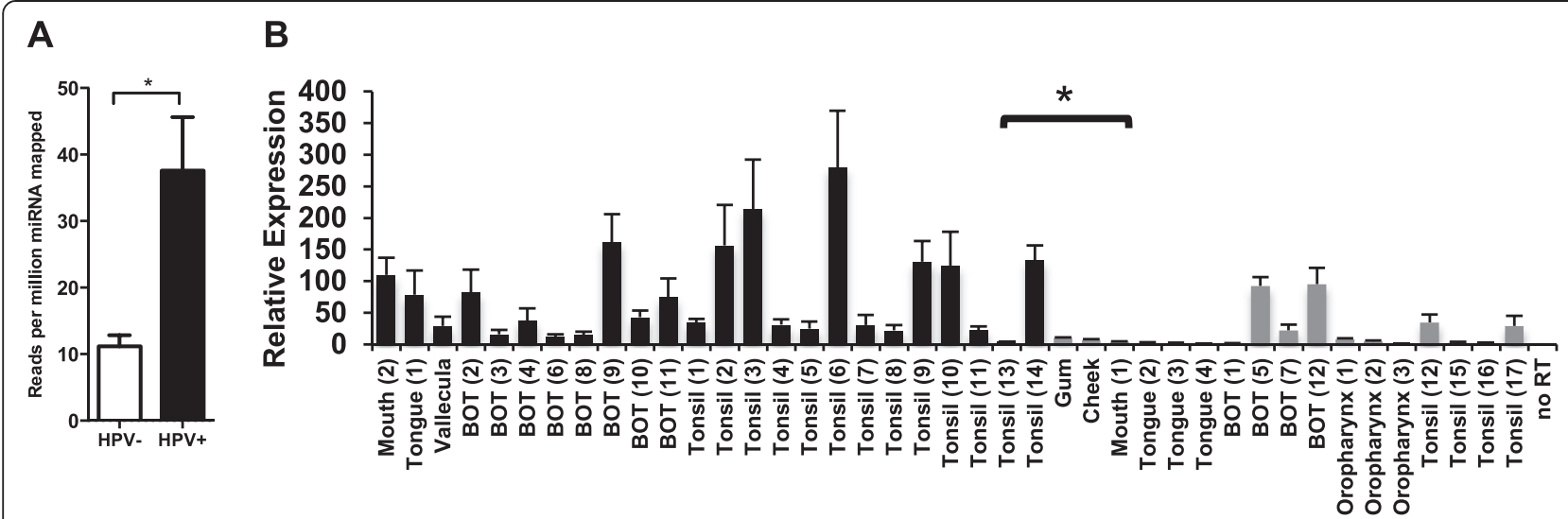

Fig. 1 MiR-363 expression in SCCHN tissues a MiR-363 expression in The Cancer Genome Atlas SCCHN tumors. HPV-negative tumors possessed an average miR-363 reads per million miRNA mapped of 11.17 while HPV-positive tumors averaged a value of 37.58, indicating a 3.36-fold increase in miR-363 expression in HPV-positive tissues; ${ }^{*} p<0.001$. b QRT-PCR analysis of miR-363 in HPV-positive and HPV-negative SCCHN tissues. Black bars, HPV-16-positive SCCHN samples; gray bars, HPV-negative SCCHN samples. Intensity values are relative to the HPV-negative SCCHN sample with the lowest miR-363 expression, which was arbitrarily assigned a value of 1 ; ${ }^{*} p<0.01$ for HPV-positive samples compared to the HPV-negative samples; BOT, base of tongue; no RT, no reverse transcriptase added

miR-363 levels compared to HPV-negative SCCHN samples as determined by qRT-PCR analysis (two-tailed $t$ test, $p<0.01$; Fig. 1b). These data are consistent with our previous in vitro studies where HPV-positive SCCHN cell lines were found to have higher levels of miR-363 expression than the HPV-negative cell lines[30].

\section{Exogenous miR-363 suppresses the migratory ability of HPV-negative SCCHN cells}

To determine the possible biological functions of miR-363, we transiently transfected HPV-negative SCCHN cell lines with premiR-363 or a negative premiR control and examined the effects on cell migration, proliferation, cell cycle and colony formation. Transwell migration assays showed a significant decrease in the number of migratory JHU028 cells overexpressing miR-363 compared to control cells at 1, 3, and $5 \mathrm{~h}$ (Fig. 2). Overexpression of miR-363 in HPV-negative SCCHN cell lines did not significantly affect cellular proliferation as examined by cell counting (Additional file 2), propidium iodide cell cycle (Additional file 3), and bromodeoxyuridine (BrdU; Additional file 4) cell cycle assays. Further, soft agar colony formation assays showed no difference in anchorage-independent growth between JHU028 cells overexpressing miR-363 and negative control cells (data not shown). Collectively, these results indicate that elevated miR-363 expression primarily reduces migration of SCCHN cell lines.

\section{MiR-363 targets the MYO1B 3' UTR and reduces MYO1B expression}

We have previously shown that 150 genes are downregulated in HPV-positive SCCHN tissues compared to
HPV-negative SCCHN[43]. Since miRNAs negatively regulate their target genes, we identified potential miR363 target genes using bioinformatic prediction tools (TargetScan, miRanda, Diana) [44-46]. A comparison of the putative target genes predicted by all three databases and the genes downregulated in HPV-positive cell lines identified 10 potential miR-363 target genes [43]. Of these, MYO1B was tested in our studies since its 3' UTR contains two potential miR-363 binding sites (see Fig. 4a).

Table 1 Detailed demographics of SCCHN tissues

\begin{tabular}{lll}
\hline & HPV-16-positive & HPV-negative \\
\hline Age, mean (SD) & $55.6(7.1)$ & $64.2(11.2)$ \\
Gender, $n$ (\%) & $20(83 \%)$ & $12(71 \%)$ \\
Males & $4(17 \%)$ & $5(29 \%)$ \\
Females & & \\
Tumor location & 1 & 3 \\
Mouth* & 1 & 3 \\
Tongue & 1 & 0 \\
Vallecula & 8 & 4 \\
Base of tongue & 0 & 3 \\
OropharynX & 13 & 4 \\
Tonsil & & \\
Tumor stage & 2 & 3 \\
T1NXMX & 21 & 5 \\
T2NXMX & 1 & 2 \\
T3NXMX & 0 & 1 \\
T4NXMX & 0 & \\
Unknown & &
\end{tabular}

* Mouth samples include mouth, gum, and cheek 

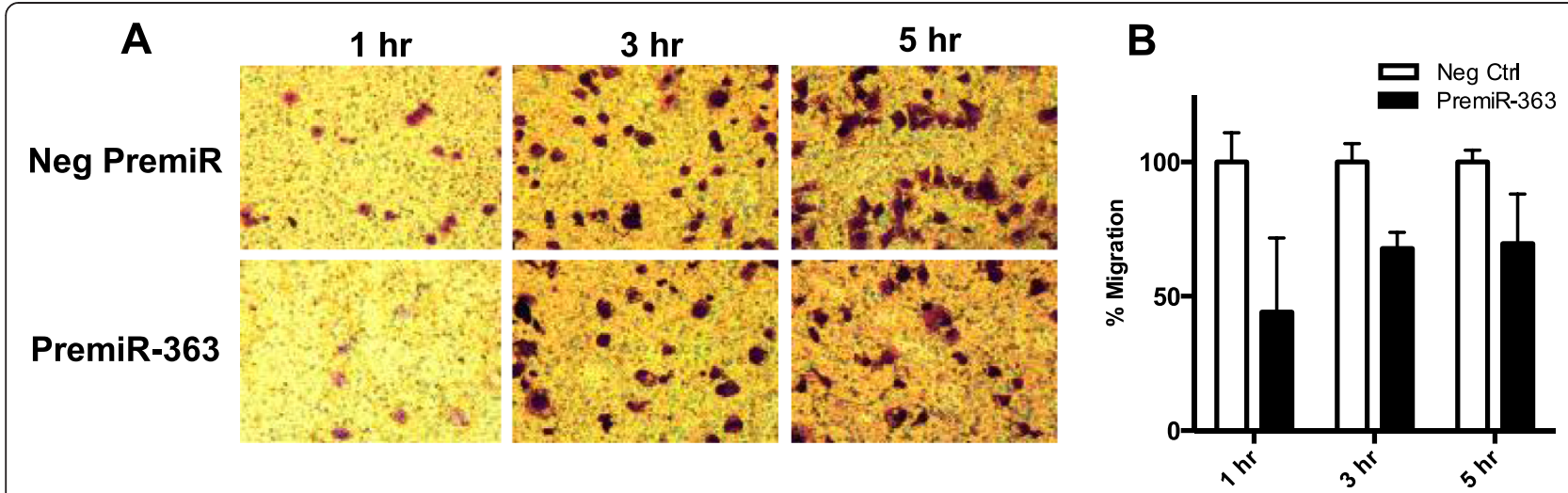

Fig. 2 MiR-363 reduces the migratory ability of HPV-negative SCCHN cells a JHU028 cells transfected with premiR-363 exhibited decreased Transwell migration at 1, 3, and $5 \mathrm{~h}$ as compared to cells transfected with a negative premiR control. $\mathbf{b}$ Quantification of cell migration data from $\mathrm{A}$. ${ }^{*} p<0.01$

Additionally, myosins are ubiquitous motor proteins involved in cellular processes such as motility [47-49].

MYO1B expression at both the mRNA and protein levels was reduced upon miR-363 overexpression in four HPV-negative SCCHN cell lines (Fig. 3). A 68-73\% decrease in MYO1B mRNA expression was noted when miR-363 was overexpressed in SCCHN cell lines. However, there was no significant difference in MYO1B protein expression between HPV-positive vs. HPV-negative and primary vs. metastatic SCCHN tumors as detected by immunohistochemistry using an oropharyngeal tissue microarray (Additional file 5). To test whether MYO1B was a direct target of miR-363, luciferase reporter assays were performed in JHU028 cells with premiR-363 and reporter plasmids (with wild-type MYO1B 3' UTR or the MYO1B 3' UTR with BS1 or BS2 deletion, cloned downstream of the firefly luciferase gene in the pMiRREPORT $^{\text {max }}$ vector). As shown in Fig. 4b, miR-363 markedly reduced firefly luciferase activity of pMiR-REPORT ${ }^{\text {TM }}$ plasmid containing the wild-type MYO1B 3' UTR or a plasmid lacking the BS2. Taken together, these studies reveal that miR-363 binding site 1 (chr2:192,288,731$192,288,738$ ) plays a functionally significant role in the regulation of MYO1B expression by this miRNA in head and neck cancer cell lines.
siRNA knockdown of MYO1B reduces cell migration in HPV-negative SCCHN cells

In order to verify whether miR-363-mediated reduction in cellular migration is directly related to decreased MYO1B expression, JHU028 cells were transfected with an siRNA against MYO1B. As shown in Fig. 5a and b, knockdown of MYO1B via siRNA in HPV-negative SCCHN cells reduced Transwell migration compared to cells expressing a negative control siRNA. These effects were similar to those obtained with miR-363 overexpression, indicating that miR-363-induced migration attenuation of SCCHN cells acts through MYO1B downregulation.

\section{Discussion}

SCCHN is a common and severe malignancy of the aerodigestive tract that is often diagnosed at late stages (III or IV). While advancements in surgery, chemotherapy, and radiation treatment have improved over time, patients often succumb to chemoradiation resistance, primary tumor invasion, metastasis, or recurrence. Notably, a number of studies indicate that HPV status is the strongest predictor of local recurrence, disease-specific survival, and overall survival in patients with SCCHN [50-52]. The heterogeneity of SCCHN malignancies

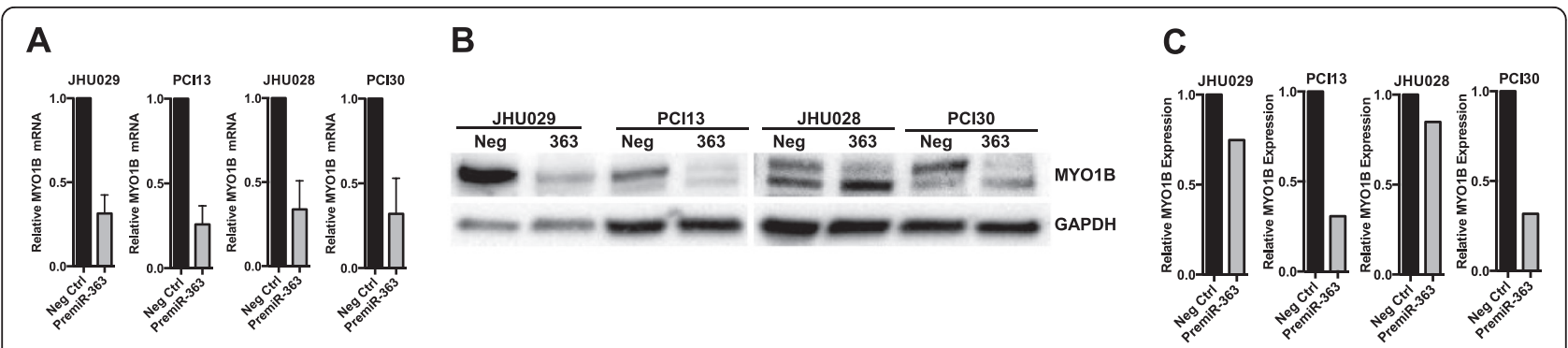

Fig. 3 MiR-363 overexpression decreases MYO1B mRNA and protein expression a qPCR analysis for relative MYO1B mRNA levels following pre-miR-363 transfection as determined by the $2^{-\Delta \Lambda C T}$ method. Data were normalized to fold induction over negative control siRNA. b Western blot analysis of MYO1B and GAPDH protein expression. c Relative MYO1B:GAPDH levels obtained from densitometry of the blot shown in B 


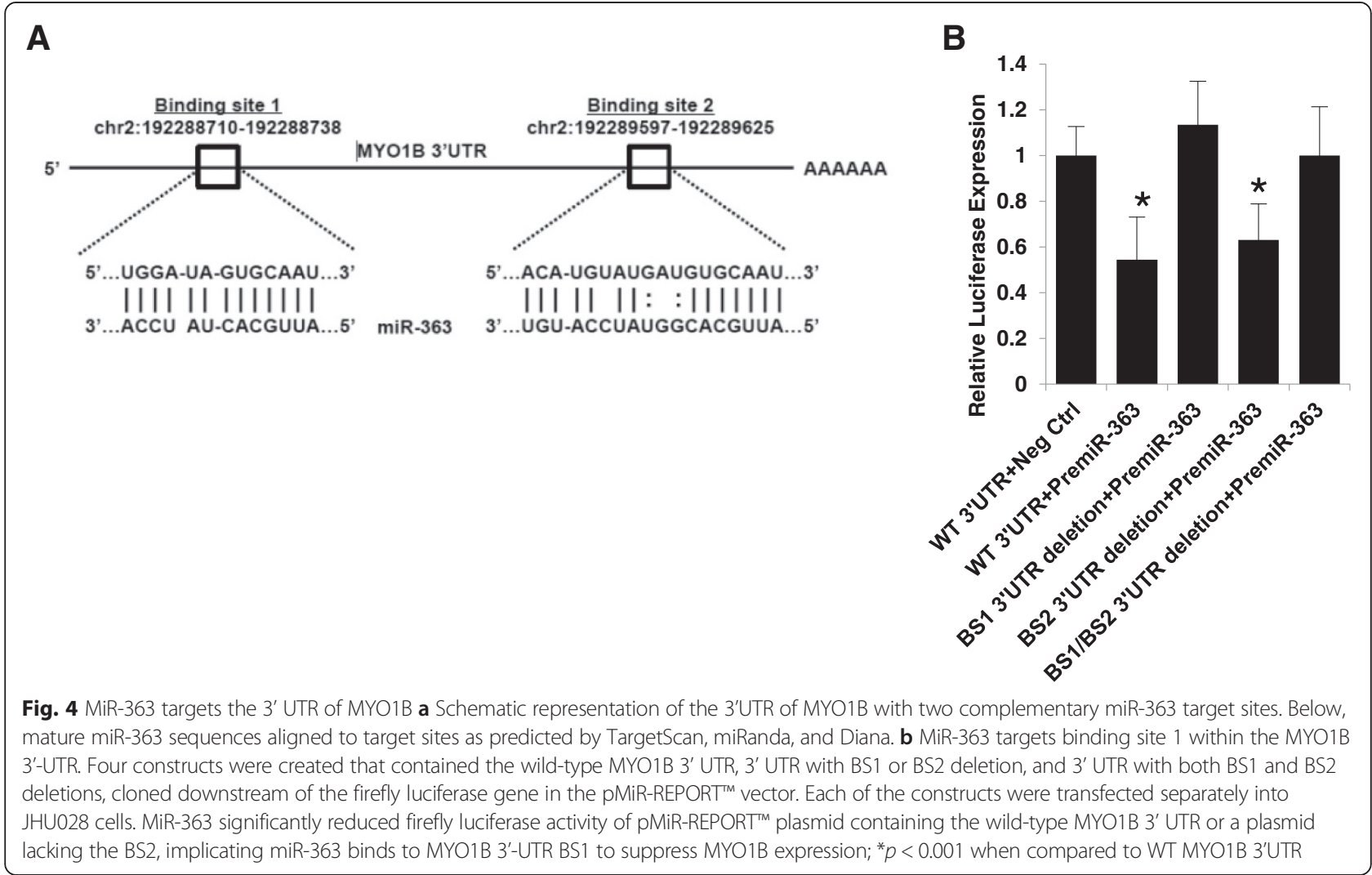

contributes to the difficulty in treating patients with generic cancer protocols; personalized treatments based on tumor signatures may serve as an efficacious complement to current standards of care. Exploiting differences in miRNA expression between HPV-positive and HPVnegative SCCHN tissues and cell lines is one method of dissecting the complexity of tumor biology.

MicroRNAs are a rapidly developing field within cancer biology. MiRNA expression profiling studies have been reported in numerous solid tumor and hematological cancers. However, among noted deregulated miRNAs, few have been functionally validated and a limited number of potential targets have been confirmed. This gap in knowledge represents a significant roadblock in the development and application of miRNA-based cancer therapeutics.

Few HPV-specific SCCHN miRNA profiling studies have been performed to date. We previously reported 11 differentially expressed miRNAs between HPV-positive and HPV-negative SCCHN cell lines [30]. Of these, three (miR-363, -497, and -33) were up-regulated and eight were down-regulated (miR-155, 181a, 181b, -29 s, -218, $-222,-221$, and $-142-5 \mathrm{p})$ in HPV-positive cell lines. Lajer et al. reported similar findings with miR-363 as the most up-regulated miRNA in HPV-associated oropharyngeal cancer in a Danish population; miR-127-3p was the most down-regulated [27]. Comparisons between HPV-positive cervical and SCCHN tumor miRNA profiles reveal that the miR-15a/miR-16/miR195/miR-497 family, miR-143/miR-145 and the miR-106-363 cluster appear to be altered by HPV E6 and E7 oncoproteins [23].

MiR-363 is a member of the miR-17 92 family of clusters, which is composed of three clusters of

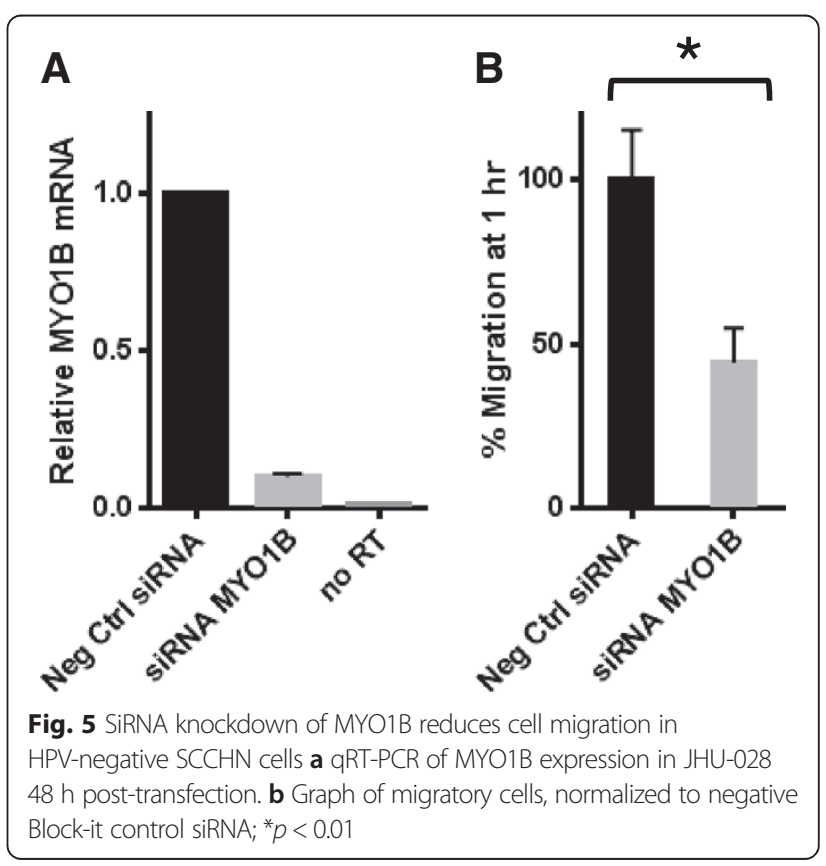


miRNAs, miR-17-92 on chromosome 13, miR-106a-363 on chromosome X, and miR-106b-25 on chromosome 7, evolved through several deletions and duplications [53]. Since miRNAs from these clusters have similar or identical seed sequences, they potentially share protein targets. Thus, it has been hypothesized that miRNAs in the miR$17 \sim 92$ family may possess related functions [32]. Researchers originally named the miR-17-92 polycistron "OncomiR-1" because the primary transcript represses $c$ myc-induced apoptosis in B-cell lymphomas [54]. Members of the OncomiR-1 family, miR-106a, $-18 b,-20 b$, $-19 \mathrm{~b},-92-2$, and -363 have been implicated in hematopoietic malignancies and solid tumors of the breast, colon, lung, pancreas, prostate, and stomach among others $[16,53,55-59]$. Conversely, the miR-1792 cluster has also been found to exhibit tumor suppressive functions. Loss of heterozygosity at the 13q12-q13 region, where the miR-17-92 cluster is located, is linked with tumor progression and poor prognosis in a number of solid tumors, including SCC of the larynx, retinoblastoma, hepatocellular carcinoma, and nasopharyngeal carcinoma [60-65]. One study observed deletion of the miR-17-92 cluster in $16.5 \%$ of ovarian cancers, $21.9 \%$ of breast cancers, and $20.0 \%$ of melanomas [66].

The precise role of miR-363 in tumorigenesis remains a controversial topic. MiR-363 has been noted to carry tumor suppressive properties in neuroblastoma, hepatocellular carcinoma, and colorectal cancer [34-36]. Recently, miR-363 has been reported to negatively regulate myeloid cell leukemia-1 (Mcl-2), an anti-apoptotic protein from the Bcl-2 family, and sensitize breast cancer cells to cisplatin [67]. Conversely, it has been shown to target pro-apoptotic caspases in glioblastoma, thereby acting as an oncomiR [68]. We speculate that the role of miRNAs as oncogenes or tumor suppressors may be tissuespecific. The targets of a particular miRNA may vary in different cell types and tissues based on the expression levels of the miRNA and its potential mRNA targets, differential expression of mRNA binding proteins, and alternative processing of mRNAs $[69,70]$. Thus, it is not always feasible to extrapolate a miRNA's functional role based on its cluster or its implication in a different tissue type.

After reporting miR-363 upregulation in HPV-positive cell lines in our previous study [30], we sought to corroborate our findings in SCCHN tumors In the present study, we confirmed miR-363 overexpression in HPV-positive tumors in TCGA and the UPCI patient cohorts. Our functional phenotypic studies revealed that miR-363 inhibits SCCHN cell migration and invasion, in part, due to inhibition of MYO1B expression. We also performed the wellestablished luciferase reporter assay, to confirm MYO1B as miR-363 target. A correlative decrease in mRNA and protein levels of MYO1B was observed following miR-363 expression. Similarly, Sun et al. correlated decreased miR363 levels in SCCHN tumor tissues with increased rates of sentinel lymph node metastasis, though HPV status was not examined [33]. This group identified another miR-363 target, podoplanin (PDPN), a protein involved in cell motility [33]. Taken together, these results suggest that the overexpression of miR-363, and subsequent decrease in MYO1B and PDPN, is one pathway by which metastasis may be reduced in HPV-positive SCCHN.

Despite having a milder clinical course, HPV-positive, p16-positive SCCHN tends to have increased nodal metastasis, but comparable rates of distant metastasis versus HPV-negative SCCHN [71, 72]. The mechanism underlying this phenomenon is yet to be elucidated. Some studies note that HPV-positivity is a factor associated with poorly differentiated tumors, which may, result in early lymphatic spread [73-75]. The heterogeneity of head and neck tumors in combination with HPV infection may cause complex molecular perturbations in the cell and differences in survival and migration pathways that are affected may affect chemotherapy or radiation resistance and therefore prognosis of HPV-positive vs. HPV-negative SCCHN. Finally, we also delineate a link between miR-363 and MYO1B in the setting of HPVpositive SCCHN.

\section{Conclusion}

In summary, we have shown that miR-363 is upregulated in HPV-positive SCCHN tumors. Through in vitro models, we have demonstrated that miR-363 decreases migration of SCCHN cells by targeting myosin $1 \mathrm{~B}$, a motility protein. The clinical relevance of increased miR363 and diminished MYO1B expression in HPV-positive SCCHN will be the subject of future investigation.

\section{Additional files}

\author{
Additional file 1: Detailed demographics of SCCHN tissues. \\ (DOCX $135 \mathrm{~kb}$ ) \\ Additional file 2: Cell counting assay. (PPTX $162 \mathrm{~kb}$ ) \\ Additional file 3: Cell cycle analysis using propidium iodide DNA \\ staining. (PPTX $54 \mathrm{~kb}$ ) \\ Additional file 4: Cell cycle analysis using bromodeoxyuridine \\ (BrdU) staining. (PPTX $59 \mathrm{~kb}$ )
}

Additional file 5: MYO1B immunohistochemistry of SCCHN primary and metastatic tumor tissue microarray. (PPTX $113 \mathrm{~kb}$ )

\section{Abbreviations}

BOT: base of tongue; HPV: human papillomavirus; miRNA, miR: microRNA; MYO1B: myosin 1B; No RT: no reverse transcriptase added; PCR: polymerase chain reaction; RISC: RNA-induced silencing complex; SCCHN: squamous cell carcinoma of the head and neck; siRNA: small interfering RNA; TCGA: The Cancer Genome Atlas. 


\section{Competing interests}

None.

\section{Authors' contributions}

BVC, AIW, PA, JRG, RLF, and SAK conceived and designed experiments. BVC, AIW, PA, ACM, JX, and SPG performed the experiments. BVC, AIW, PA, ACM, JX, and SAK analyzed the data. BVC, AIW, and SAK wrote the manuscript. All authors read and approved the final manuscript.

\section{Acknowledgements}

This study was supported by the NIH grant 1R21 DE021881 to SAK. BVC was supported by the HHMI Medical Fellows Research Program and the Physician Scientist Training Program at the University of Pittsburgh School of Medicine. The results published here are in part based upon data generated by the TCGA Research Network: http://cancergenome.nih.gov/.

\section{Author details}

${ }^{1}$ Department of Microbiology and Molecular Genetics, University of Pittsburgh School of Medicine, Pittsburgh, PA 15219, USA. ${ }^{2}$ Department of Immunology, University of Pittsburgh, Pittsburgh, PA 15216, USA. ${ }^{3}$ Department of Otolaryngology, University of Pittsburgh and University of Pittsburgh Cancer Institute, Pittsburgh, PA 15213, USA. ${ }^{4}$ Department of Pharmacology and Chemical Biology, University of Pittsburgh and University of Pittsburgh Cancer Institute, Pittsburgh, PA 15213, USA. ${ }^{5}$ Present address: Clinical and Translational Science Institute Floor, San Francisco, CA 94158, USA. ${ }^{6}$ Medical Research Fellows Program, Howard Hughes Medical Institute, Chevy Chase, MD 20815, USA.

\section{Received: 27 May 2015 Accepted: 30 October 2015}

\section{Published online: 06 November 2015}

\section{References}

1. Leemans $C R$, Braakhuis BJ, Brakenhoff $\mathrm{RH}$. The molecular biology of head and neck cancer. Nat Rev Cancer. 2011;11(1):9-22.

2. Stransky N, Egloff AM, Tward AD, Kostic AD, Cibulskis K, Sivachenko A, et al. The mutational landscape of head and neck squamous cell carcinoma. Science. 2011;333(6046):1157-60.

3. Gillison ML. Current topics in the epidemiology of oral cavity and oropharyngeal cancers. Head Neck. 2007;29(8):779-92.

4. Bauman JE, Michel LS, Chung $\mathrm{CH}$. New promising molecular targets in head and neck squamous cell carcinoma. Curr Opin Oncol. 2012;24(3):235-42.

5. Marur S, D'Souza G, Westra WH, Forastiere AA. HPV-associated head and neck cancer: a virus-related cancer epidemic. Lancet Oncol. 2010;11(8):781-9.

6. Shi W, Kato H, Perez-Ordonez B, Pintilie M, Huang S, Hui A, et al. Comparative prognostic value of HPV16 E6 mRNA compared with in situ hybridization for human oropharyngeal squamous carcinoma. J clin oncol : official journal of the American Society of Clinical Oncology. 2009;27(36):6213-21.

7. Klussmann JP, Weissenborn SJ, Wieland U, Dries V, Kolligs J, Jungehuelsing $M$, et al. Prevalence, distribution, and viral load of human papillomavirus 16 DNA in tonsillar carcinomas. Cancer. 2001;92(11):2875-84.

8. Vidal L, Gillison ML. Human papillomavirus in HNSCC: recognition of a distinct disease type. Hematol Oncol Clin North Am. 2008;22(6):1125-42. vii.

9. Albers A, Abe K, Hunt J, Wang J, Lopez-Albaitero A, Schaefer C, et al. Antitumor activity of human papillomavirus type 16 E7-specific T cells against virally infected squamous cell carcinoma of the head and neck. Cancer Res. 2005;65(23):11146-55.

10. Ragin CC, Taioli E. Survival of squamous cell carcinoma of the head and neck in relation to human papillomavirus infection: review and metaanalysis. Int j cancer Journal international du cancer. 2007;121(8):1813-20.

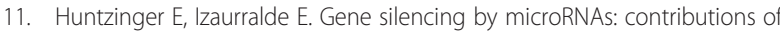
translational repression and mRNA decay. Nat Rev Genet. 2011;12(2):99-110.

12. Friedman RC, Farh KK, Burge CB, Bartel DP. Most mammalian mRNAs are conserved targets of microRNAs. Genome Res. 2009;19(1):92-105.

13. Lee $Y$, Jeon K, Lee JT, Kim S, Kim VN. MicroRNA maturation: stepwise processing and subcellular localization. EMBO J. 2002;21(17):4663-70.

14. Bartel DP. MicroRNAs: genomics, biogenesis, mechanism, and function. Cell. 2004;116(2):281-97.

15. Calin GA, Dumitru CD, Shimizu M, Bichi R, Zupo S, Noch E, et al. Frequent deletions and down-regulation of micro- RNA genes miR15 and miR16 at
$13 q 14$ in chronic lymphocytic leukemia. Proc Natl Acad Sci U S A. 2002:99(24):15524-9.

16. Volinia S, Calin GA, Liu CG, Ambs S, Cimmino A, Petrocca F, et al. A microRNA expression signature of human solid tumors defines cancer gene targets. Proc Natl Acad Sci U S A. 2006;103(7):2257-61.

17. Garzon R, Croce CM. MicroRNAs in normal and malignant hematopoiesis. Curr Opin Hematol. 2008;15(4):352-8.

18. Garzon R, Calin GA, Croce CM. MicroRNAs in Cancer. Annu Rev Med. 2009;60:167-79.

19. Lu J, Getz G, Miska EA, Alvarez-Saavedra E, Lamb J, Peck D, et al. MicroRNA expression profiles classify human cancers. Nature. 2005;435(7043):834-8.

20. Ramdas L, Giri U, Ashorn CL, Coombes KR, El-Naggar A, Ang KK. miRNA expression profiles in head and neck squamous cell carcinoma and adjacent normal tissue. Head Neck. 2009;31(5):642-54.

21. Gao G, Gay HA, Chernock RD, Zhang TR, Luo J, Thorstad WL, et al. A microRNA expression signature for the prognosis of oropharyngeal squamous cell carcinoma. Cancer. 2013;119(1):72-80.

22. Hsu CM, Lin PM, Wang YM, Chen ZJ, Lin SF, Yang MY. Circulating miRNA is a novel marker for head and neck squamous cell carcinoma. Tumour biol : the journal of the International Society for Oncodevelopmental Biology and Medicine. 2012;33(6):1933-42.

23. Lajer CB, Garnaes E, Friis-Hansen L, Norrild B, Therkildsen MH, Glud M, et al. The role of miRNAs in human papilloma virus (HPV)-associated cancers: bridging between HPV-related head and neck cancer and cervical cancer. $\mathrm{Br}$ J Cancer. 2012;106(9):1526-34.

24. Kaczkowski B, Morevati M, Rossing M, Cilius F, Norrild B. A Decade of Global mRNA and miRNA Profiling of HPV-Positive Cell Lines and Clinical Specimens. The open virology journal. 2012;6:216-31.

25. Song $X$, Sturgis EM, Liu J, Jin L, Wang Z, Zhang C, et al. MicroRNA variants increase the risk of HPV-associated squamous cell carcinoma of the oropharynx in never smokers. PLoS One. 2013;8(2), e56622.

26. Chang SS, Jiang WW, Smith I, Poeta LM, Begum S, Glazer C, et al. MicroRNA alterations in head and neck squamous cell carcinoma. Int j cancer Journal international du cancer. 2008;123(12):2791-7.

27. Lajer CB, Nielsen FC, Friis-Hansen L, Norrild B, Borup R, Garnaes E, et al. Different miRNA signatures of oral and pharyngeal squamous cell carcinomas: a prospective translational study. $\mathrm{Br} J$ Cancer. 2011;104(5):830-40

28. Avissar M, Christensen BC, Kelsey KT, Marsit CJ. MicroRNA expression ratio is predictive of head and neck squamous cell carcinoma. Clin cancer res : an official journal of the American Association for Cancer Research. 2009;15(8):2850-5.

29. Tran N, McLean T, Zhang X, Zhao CJ, Thomson JM, O'Brien C, et al. MicroRNA expression profiles in head and neck cancer cell lines. Biochem Biophys Res Commun. 2007;358(1):12-7.

30. Wald Al, Hoskins EE, Wells SI, Ferris RL, Khan SA. Alteration of microRNA profiles in squamous cell carcinoma of the head and neck cell lines by human papillomavirus. Head Neck. 2011;33(4):504-12.

31. Hui AB, Lenarduzzi M, Krushel T, Waldron L, Pintilie M, Shi W, et al. Comprehensive MicroRNA profiling for head and neck squamous cell carcinomas. Clin cancer res : an official journal of the American Association for Cancer Research. 2010;16(4):1129-39.

32. Ventura A, Young AG, Winslow MM, Lintault L, Meissner A, Erkeland SJ, et al. Targeted deletion reveals essential and overlapping functions of the miR-17 through 92 family of miRNA clusters. Cell. 2008;132(5):875-86

33. Sun Q, Zhang J, Cao W, Wang X, Xu Q, Yan M, et al. Dysregulated miR363 affects head and neck cancer invasion and metastasis by targeting podoplanin. Int J Biochem Cell Biol. 2012;45(3):513-20

34. Tsuji S, Kawasaki Y, Furukawa S, Taniue K, Hayashi T, Okuno M, et al. The miR-363-GATA6-Lgr5 pathway is critical for colorectal tumourigenesis. Nat Commun. 2014;5:3150.

35. Zhou P, Huang G, Zhao Y, Zhong D, Xu Z, Zeng Y, et al. MicroRNA-363-mediated downregulation of S1PR1 suppresses the proliferation of hepatocellular carcinoma cells. Cell Signal. 2014;26(6):1347-54.

36. Qiao J, Lee S, Paul P, Theiss L, Tiao J, Qiao L, et al. miR-335 and miR-363 regulation of neuroblastoma tumorigenesis and metastasis. Surgery. 2013;154(2):226-33.

37. Wessels D, Murray J, Jung G, Hammer 3rd JA, Soll DR. Myosin IB null mutants of Dictyostelium exhibit abnormalities in motility. Cell Motil Cytoskeleton. 1991;20(4):301-15. 
38. Wilson AK, Pollenz RS, Chisholm RL, de Lanerolle P. The role of myosin I and II in cell motility. Cancer Metastasis Rev. 1992;11(1):79-91.

39. Cerami E, Gao J, Dogrusoz U, Gross BE, Sumer SO, Aksoy BA, et al. The cBio cancer genomics portal: an open platform for exploring multidimensional cancer genomics data. Cancer discovery. 2012;2(5):401-4.

40. Ferris RL, Martinez I, Sirianni N, Wang J, Lopez-Albaitero A, Gollin SM, et al. Human papillomavirus-16 associated squamous cell carcinoma of the head and neck (SCCHN): a natural disease model provides insights into viral carcinogenesis. Eur J Cancer. 2005;41(5):807-15.

41. Livak KJ, Schmittgen TD. Analysis of relative gene expression data using real-time quantitative PCR and the 2(-Delta Delta C(T)) Method. Methods. 2001;25(4):402-8.

42. Cancer Genome Atlas N. Comprehensive genomic characterization of head and neck squamous cell carcinomas. Nature. 2015;517(7536):576-82.

43. Martinez I, Wang J, Hobson KF, Ferris RL, Khan SA. Identification of differentially expressed genes in HPV-positive and HPV-negative oropharyngeal squamous cell carcinomas. Eur J Cancer. 2007:43(2):415-32.

44. Alexiou P, Maragkakis M, Papadopoulos GL, Simmosis VA, Zhang L, Hatzigeorgiou AG. The DIANA-mirExTra web server: from gene expression data to microRNA function. PLoS One. 2010;5(2), e9171.

45. Lewis BP, Burge CB, Bartel DP. Conserved seed pairing, often flanked by adenosines, indicates that thousands of human genes are microRNA targets. Cell. 2005;120(1):15-20.

46. Stuttgen U. Non-precious alloy double crowns. Dental technic position. Zahnarztl Prax. 1990;41(1):10-2. 13.

47. Almeida CG, Yamada A, Tenza D, Louvard D, Raposo G, Coudrier E. Myosin $1 \mathrm{~b}$ promotes the formation of post-Golgi carriers by regulating actin assembly and membrane remodelling at the trans-Golgi network. Nat Cell Biol. 2011;13(7):779-89.

48. Komaba S, Coluccio LM. Localization of myosin $1 \mathrm{~b}$ to actin protrusions requires phosphoinositide binding. J Biol Chem. 2010;285(36):27686-93.

49. Tsiavaliaris G, Fujita-Becker S, Durrwang U, Diensthuber RP, Geeves MA, Manstein DJ. Mechanism, regulation, and functional properties of Dictyostelium myosin-1B. J Biol Chem. 2008;283(8):4520-7.

50. Ang KK, Harris J, Wheeler R, Weber R, Rosenthal DI, Nguyen-Tan PF, et al. Human papillomavirus and survival of patients with oropharyngeal cancer. N Engl J Med. 2010;363(1):24-35.

51. Fakhry C, Westra WH, Li S, Cmelak A, Ridge JA, Pinto H, et al. Improved survival of patients with human papillomavirus-positive head and neck squamous cell carcinoma in a prospective clinical trial. J Natl Cancer Inst. 2008;100(4):261-9.

52. Cmelak AJ. Current issues in combined modality therapy in locally advanced head and neck cancer. Crit Rev Oncol Hematol. 2012:84(2):261-73.

53. Olive $\mathrm{V}$, Jiang I, He L. mir-17-92, a cluster of miRNAs in the midst of the cancer network. Int J Biochem Cell Biol. 2010;42(8):1348-54.

54. He L, Thomson JM, Hemann MT, Hernando-Monge E, Mu D, Goodson S, et al. A microRNA polycistron as a potential human oncogene. Nature. 2005:435(7043):828-33.

55. Petrocca F, Vecchione A, Croce CM. Emerging role of miR-106b-25/miR-17-92 clusters in the control of transforming growth factor beta signaling. Cancer Res. 2008;68(20):8191-4.

56. Landais S, Landry S, Legault P, Rassart E. Oncogenic potential of the miR-106363 cluster and its implication in human T-cell leukemia. Cancer Res. 2007:67(12):5699-707

57. Hayashita Y, Osada H, Tatematsu Y, Yamada H, Yanagisawa K, Tomida S, et al. A polycistronic microRNA cluster, miR-17-92, is overexpressed in human lung cancers and enhances cell proliferation. Cancer Res. 2005;65(21):9628-32.

58. Ota A, Tagawa H, Karnan S, Tsuzuki S, Karpas A, Kira S, et al. Identification and characterization of a novel gene, C13orf25, as a target for 13q31-q32 amplification in malignant lymphoma. Cancer Res. 2004;64(9):3087-95.

59. Takakura S, Mitsutake N, Nakashima M, Namba H, Saenko VA, Rogounovitch TI, et al. Oncogenic role of miR-17-92 cluster in anaplastic thyroid cancer cells. Cancer Sci. 2008;99(6):1147-54.

60. Stembalska A, Blin N, Ramsey D, Sasiadek MM. Three distinct regions of deletion on $13 \mathrm{q}$ in squamous cell carcinoma of the larynx. Oncol Rep. 2006;16(2):417-21.

61. Zhang XL, Fu WL, Zhao HX, Zhou LX, Huang JF, Wang JH. Molecular studies of loss of heterozygosity in Chinese sporadic retinoblastoma patients. Clin chim acta; international journal of clinical chemistry. 2005;358(1-2):75-80.

62. Lin YW, Sheu JC, Liu LY, Chen CH, Lee HS, Huang GT, et al. Loss of heterozygosity at chromosome $13 \mathrm{q}$ in hepatocellular carcinoma: identification of three independent regions. Eur J Cancer. 1999;35(12):1730-4.
63. Eiriksdottir $G$, Johannesdottir $G$, Ingvarsson S, Bjornsdottir IB, Jonasson JG, Agnarsson BA, et al. Mapping loss of heterozygosity at chromosome 13q: loss at 13q12-q13 is associated with breast tumour progression and poor prognosis. Eur J Cancer. 1998;34(13):2076-81.

64. Lo KW, Teo PM, Hui AB, To KF, Tsang YS, Chan SY, et al. High resolution allelotype of microdissected primary nasopharyngeal carcinoma. Cancer Res. 2000;60(13):3348-53.

65. Shao J, Li Y, Wu Q, Liang $X, Y u X$, Huang $L$, et al. High frequency loss of heterozygosity on the long arms of chromosomes 13 and 14 in nasopharyngeal carcinoma in Southern China. Chin Med J (Engl). 2002;115(4):571-5.

66. Zhang L, Huang J, Yang N, Greshock J, Megraw MS, Giannakakis A, et al. microRNAs exhibit high frequency genomic alterations in human cancer. Proc Natl Acad Sci U S A. 2006;103(24):9136-41.

67. Zhang R, Li Y, Dong X, Peng L, Nie X. MiR-363 sensitizes cisplatin-induced apoptosis targeting in Mcl-1 in breast cancer. Med Oncol. 2014;31(12):347.

68. Floyd DH, Zhang Y, Dey BK, Kefas B, Breit H, Marks K, et al. Novel AntiApoptotic MicroRNAs 582-5p and 363 Promote Human Glioblastoma Stem Cell Survival via Direct Inhibition of Caspase 3, Caspase 9, and Bim. PLoS One. 2014;9(5), e96239.

69. Bartel DP. MicroRNAs: target recognition and regulatory functions. Cell. 2009;136(2):215-33.

70. Nam JW, Rissland OS, Koppstein D, Abreu-Goodger C, Jan CH, Agarwal V, et al. Global analyses of the effect of different cellular contexts on microRNA targeting. Mol Cell. 2014;53(6):1031-43.

71. Mendelsohn AH, Lai CK, Shintaku IP, Elashoff DA, Dubinett SM, Abemayor E, et al. Histopathologic findings of HPV and p16 positive HNSCC. Laryngoscope. 2010;120(9):1788-94.

72. Rischin D, Young RJ, Fisher R, Fox SB, Le QT, Peters LJ, et al. Prognostic significance of p16INK4A and human papillomavirus in patients with oropharyngeal cancer treated on TROG 02.02 phase III trial. J clin oncol : off j Am Soc Clin Oncol. 2010;28(27):4142-8.

73. Haraf DJ, Nodzenski E, Brachman D, Mick R, Montag A, Graves D, et al. Human papilloma virus and p53 in head and neck cancer: clinical correlates and survival. Clin cancer res : an official journal of the American Association for Cancer Research. 1996;2(4):755-62.

74. Lajer CB, von Buchwald C. The role of human papillomavirus in head and neck cancer. APMIS : acta pathol, microbiol, et immunol Scand. 2010;118(6-7):510-9.

75. Paz IB, Cook N, Odom-Maryon T, Xie Y, Wilczynski SP. Human papillomavirus (HPV) in head and neck cancer. An association of HPV 16 with squamous cell carcinoma of Waldeyer's tonsillar ring. Cancer. 1997;79(3):595-604.

\section{Submit your next manuscript to BioMed Central and take full advantage of:}

- Convenient online submission

- Thorough peer review

- No space constraints or color figure charges

- Immediate publication on acceptance

- Inclusion in PubMed, CAS, Scopus and Google Scholar

- Research which is freely available for redistribution 